\section{Orbital Myositis and Primary Sjögren Syndrome}

\section{To the Editor:}

In this report, we describe a new systemic manifestation associated with primary Sjögren syndrome (pSS): orbital myositis (OM). Considered a systemic disorder, pSS is primarily characterized by lymphocytic infiltration of exocrine glands, resulting in functional impairment of salivary and lacrymal glands. The inflammatory process, however, extends beyond the exocrine glands and can potentially affect any organ.

A 40-year-old white man with pSS was admitted with diplopia. Since 2002, his disease manifested with sicca syndrome, polyarthralgia, antinuclear antibodies, and anti-SSA and -SSB antibodies, and lymphocytic sialadenitis (focus score of 1) associated with Hashimoto thyroiditis. He previously developed 2 neurological complications: aseptic meningoradiculitis following treatment with infliximab in 2002 (in the Trial of Remicade in Primary Sjögren's Syndrome randomized clinical trial) ${ }^{1}$, and bilateral idiopathic sudden sensorineural hearing loss in 2010.

In January 2014, he presented with vertical, binocular diplopia with conjunctival hyperemia, palpebral edema, and polyarthralgia. Examination revealed infracentimetrics axillary and inguinal lymphadenopathies without parotid gland swelling. Ophthalmologic examination did not reveal ophthalmoplegia, visual field defect, or accommodative trouble; slit lamp and retinal examination was normal. Pupil light reflexes were normal. Clinical examination was otherwise normal. Cerebral magnetic resonance imaging (MRI) showed a hypersignal of the superior rectus orbital muscle on the right side on $\mathrm{T} 2$-weighted sequences leading to diagnosis of OM (Figure 1).

Biological examination showed lymphopenia at $710 / \mathrm{mm}^{3}$ with erythrocyte sedimentation rate at $50 \mathrm{~mm} / \mathrm{h}$ and C-reactive protein at $16 \mathrm{mg} / \mathrm{l}$ Thyroid function was normal and thyroid-stimulation hormone-receptor antibody was negative. Rheumatoid factor was positive at $79 \mathrm{UI} / \mathrm{ml}$. Complement factor $\mathrm{C} 3$ was normal at $1.15 \mathrm{~g} / 1$ (normal range $0.8-1.54$ ) and $\mathrm{C} 4$ rate was low at $0.14 \mathrm{~g} / \mathrm{l}$ (normal range 0.18-0.42). Ratio of kappa/lambda serum-free light chain of immunoglobulins was normal. Cryoglobulinemia tests were negative and serum $\operatorname{IgG}$ rate was increased $(16.5 \mathrm{~g} / 1$, normal range $8-13.5 \mathrm{~g} / \mathrm{l}$ ), but immunoglobulin G4 (IgG4) serum level was low

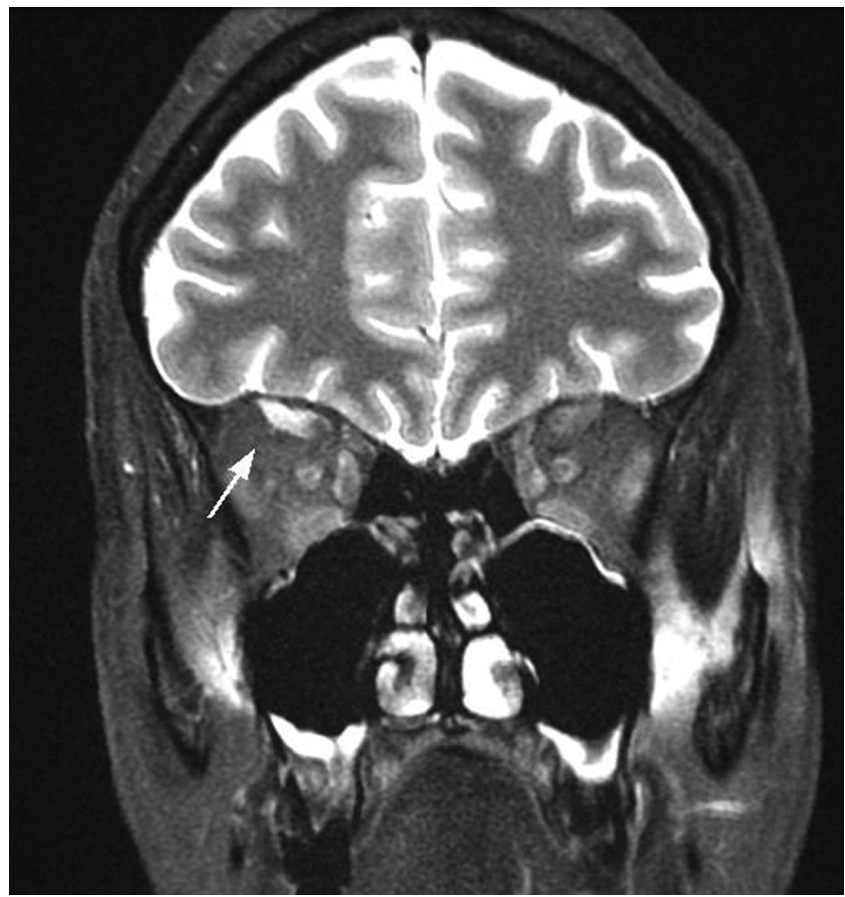

Figure 1. Inflammatory edema of the right superior rectus orbital muscle on cerebral MRI T2-weighted coronal sequence. MRI: magnetic resonance imaging.
$(<0.04 \mathrm{~g} / \mathrm{l})$. Antineutrophil cytoplasmic, antiaquaporin 4, anti-DNA, anticardiolipin, and anti- $\beta 2$ GP1 antibodies were negative. Serodiagnosis for human immunodeficiency virus 1 and 2, Lyme, and syphilitic diseases were negative. Cerebrospinal fluid showed mildly elevated protein $(0.55 \mathrm{~g} / \mathrm{l})$ and normal glucose rate $(2.9 \mathrm{mmol} / \mathrm{l})$ without any pleocytosis $(3$ white blood cells $/ \mathrm{mm}^{3}$ ). Tomodensitometry revealed only infracentimetric axillary, mediastinal, and inguinal lymphadenopathies.

A new labial minor salivary gland biopsy confirmed lymphocytic sialadenitis (focus score 1.12 with no germinal center), but did not reveal IgG4 plasma cells or B cell lymphoma. Inguinal lymphadenopathy biopsy demonstrated reactive lymphadenitis without lymphoma or granulomatosis. We did not perform orbital muscle biopsy because MRI features were not suggestive of malignant disease and clinical course was spontaneously favorable.

OM associated with a pSS was diagnosed. Hydroxychloroquine 400 $\mathrm{mg} /$ day was initiated to prevent relapse without prednisone because of spontaneous regression of symptoms. Six months later, clinical examination confirmed complete resolution.

$\mathrm{OM}$ is a rare idiopathic inflammatory disease, classified as part of orbital inflammatory disease $e^{2,3}$ and defined by inflammation of the extraocular orbital muscles. Clinical characteristics include orbital pain, diplopia, proptosis, swollen eyelids, and conjunctival hyperemia. Recognized causes are autoimmune thyroid (Graves disease), antineutrophil cytoplasmic antibodies-associated vasculitis, sarcoidosis, and systemic lupus erythematosus $s^{4,5,6}$, and recently, observations of OM have been described in IgG4-related disease ${ }^{7}$. Several inflammatory diseases have also been reported associated with OM: Crohn disease and Behçet disease. Differential diagnoses include orbital cellulitis, non-Hodgkin lymphomas, metastatic solid cancer, and melanoma. To our knowledge, this is the first case report of OM in the context of pSS.

Of the autoimmune diseases, pSS is most commonly associated with non-Hodgkin lymphoma ${ }^{8}$. We here described an atypical ocular manifestation, initially suggestive of lymphoma, but investigation and spontaneous regression revealed a new extraglandular association with pSS that is idiopathic myositis.

FRANÇOIS-XAVIER DANLOS, MD; FADELA DAOUED, MD; RAPHAÈLE SEROR, MD, PhD; XAVIER MARIETTE, MD, PhD, Service de Rhumatologie, Hôpital Bicêtre, Le Kremlin Bicêtre, France. Address correspondence to Dr. X. Mariette, Hôpitaux Universitaires Paris-Sud, Assistance Publique des Hôpitaux de Paris, Hôpital Bicêtre, Service de Rhumatologie, 78 rue du Général Leclerc, Le Kremlin Bicêtre 94275 , France.E-mail: xavier.mariette@bct.aphp.fr

\section{REFERENCES}

1. Mariette X, Ravaud P, Steinfeld S, Baron G, Goetz J, Hachulla E, et al. Inefficacy of infliximab in primary Sjögren's syndrome: results of the randomized, controlled Trial of Remicade in Primary Sjögren's Syndrome (TRIPSS). Arthritis Rheum 2004;50:1270-6.

2. Costa RM, Dumitrascu OM, Gordon LK. Orbital myositis: diagnosis and management. Curr Allergy Asthma Rep 2009; 9:316-23.

3. Lutt JR, Lim LL, Phal PM, Rosenbaum JT. Orbital inflammatory disease. Semin Arthritis Rheum 2008;37:207-22.

4. Kono S, Takashima H, Suzuki D, Terada T, Konishi T, Miyajima H Orbital myositis associated with discoid lupus erythematosus. Lupus 2014;23:220-2.

5. Santosa A, Vasoo S. Orbital myositis as manifestation of systemic lupus erythematosus - a case report. Postgrad Med J 2013;89:59.

6. Plaza JA, Garrity JA, Dogan A, Ananthamurthy A, Witzig TE, Salomão DR. Orbital inflammation with IgG4-positive plasma cells: manifestation of IgG4 systemic disease. Arch Ophthalmol 2011;129:421-8

7. Arrico L, Abbouda A, Bianchi S, Malagola R. Acute monolateral proptosis and orbital myositis in a patient with discoid lupus 
erythematosus: a case report. J Med Case Rep 2014;8:375.

8. Smedby KE, Baecklund E, Askling J. Malignant lymphoma in

autoimmunity and inflammation: a review of risks, risks factors, and

lymphomas characteristics. Cancer Epidemiol Biomarkers Prev 2006;15:2069-77.

J Rheumatol 2015;42:8; doi:10.3899/jrheum.141318 